\title{
POSTER MANFAAT WPAP SEBAGAI ALTERNATIF GAYA DALAM PENYAMPAIAN INFORMASI PENGETAHUAN
}

\author{
Ayu Hanifah Nida ${ }^{1)}$, Jaya Sumantri ${ }^{2)}$ \\ Program Studi Desain Komunikasi Visual \\ Fakultas Bahasa dan Seni, Universitas Indraprasta PGRI \\ Jl. Nangka No. 58 C, Tanjung Barat, Jakarta Selatan, 12530, Indonesia \\ ayuhanifah111@gmail.com
}

\begin{abstract}
Abstrak
WPAP (Wedha's Pop Art Potrait) merupakan gaya melukis Pop Art yang diciptakan oleh bapak Wedha Abdul Rasyid. WPAP memiliki beberapa manfaat yaitu sebagai media megekspresikan seni, karya yang memiliki nilai ekonomis, media memorial sekaligus apresiasi, media pembelajaran, dan juga bisa menjadi media promosi. Atas dasar tersebut, kami membuat perancangan media berupa poster sebagai media penyampaian informasi pengetahuan mengenai manfaat WPAP. Dengan menggunakan metode kualitatif, diperoleh data berupa kualitatif sekunder. Dari hasil analisis data dan pertimbangan dalam perancangan kami dapati hasil perancangannya yaitu dengan menggunakan layout dibuat dengan membagi 2 space atas bawah dengan bagian atas untuk contoh gambar WPAPnya sedangkan bagian bawah untuk informasinya, warna yang digunakan ada 2 macam yaitu warna kuning langsat dan abu-abu yang difungsikan untuk background sedangkan untuk tipografinyanya menggunakan biru dongker, menggunakan gaya ilustrasi discord, serta tipografi yang menggunakan jenis huruf san serif. Poster tersebut bisa dijadikan sebagai media informasi cetak maupun digital (diposting di media sosial).
\end{abstract}

Kata Kunci: Poster, Manfaat WPAP, Alternatif Gaya, Penyampaian Informasi, Pengetahuan

\begin{abstract}
WPAP (Wedha's Pop Art Potrait) is a Pop Art painting style created by Mr. Wedha Abdul Rasyid. WPAP has several benefits, namely as a media to express art, works that have economic value, memorial media as well as appreciation, learning media, and can also be a promotional media. On this basis, we created a media design in the form of a poster as a medium for delivering knowledge information about the benefits of WPAP. By using qualitative methods, obtained in the form of secondary qualitative data. From the results of data analysis and considerations in the design we found that the design results are by using a layout created by dividing the top 2 space below with the top for examples of WPAP images while the bottom for information, there are 2 kinds of colors used, namely yellow and gray which is used for the background while for typography using blue dongker, using a discord illustration style, and typography using san serif typeface. The poster can be used as print and digital information media (posted on social media).
\end{abstract}

Keywords: Poster, Benefits of WPAP, Alternative Styles, Submission of Information, Knowledge

Correspondence author: Ayu Hanifah Nida, ayuhanifah111@gmail.com, Jakarta, and Indonesia 


\section{PENDAHULUAN}

Jika membicarakan karya maka pada umumnya akan tertuju juga pada kata seni. Namun apakah seni itu sendiri. Seni Dalam hal membahas seni, terutama seni rupa yang memiliki banyak aliran yaitu seni rupa romantisme, naturalisme, futurisme, realisme, surealisme, post modern/kontemporer, dan yang lainnya. Banyaknya jenis seni dan dari beberapanya ada yang berkembang mengikuti, seperti seni yang sudah digital sebagai medianya. Namun dalam beberapa jenis tersebut ada jenis seni yang diciptakan oleh seniman pop art Indonesia yaitu Wedha Abdul Rasyid. Beliau yang membuat dan mempelopori teknik baru seni WPAP hingga diakui oleh dunia (Dawami, 2016).

WPAP merupakan suatu jenis seni yang tekniknya menggunakan bidang geometris dalam membentuk objek khususnya wajah manusia dengan perpaduan warna pop art. Dari WPAP tersebut kami membahas Semiotikanya dan mencari manfaat umum dengan adanya WPAP. Pop Art sendiri secara umumnya memiliki pengertian sebagai seni yang memakai gaya visual tersendiri dalam tampilannya. Dari sekian banyak aliran, aliran seni yang cukup mengesankan dilihat dari beberapa sudut pandang dan aspek yaitu aliran pop art karena tampilan warnanya lebih kontras tetapi tidak serealis dari aliran lainnya serta gambarnya bisa menggambarkan kritikan, humor maupun sindiran. Namun seni pop Art ini tetap dapat dinikmati oleh semua kalangan. Seniman pop art yang paling tersohor di dunia ialah seorang seniman Amerika Serikat yang bernama Andy Warhol, dengan karyanya yang menggambarkan wajah Marylin Monroe. Selain itu, Andy Warhol yang mulai memopulerkan pop art di Amerika dan seluruh dunia. Sedangkan senimanm pop art terkemuka dari Indonesia adalah Wedha Abdul Rasyid yang sekaligus mempelopori penciptaan teknik baru yang diakui oleh dunia yaitu Wedha's Pop Art Portrait atau disingkat WPAP (Dawami, 2016).

Tampilan WPAP sendiri berbeda dengan pop art aslinya meskipun objeknya masih tetap menggambarkan wajah manusia tetapi susunan yang membentuk gambar manusianya itu terdiri dari bentuk-bentuk geometris sekilas polanya mirip dengan mozaik. Pada awalnya Wedha membuat desain pop art ini masih dalam warna yang realis tetapi karena faktor usia, Wedha sulit membedakan warna wajah realisme. Lalu terlintas dipikiran beliau sehingga menggantikan bentuk wajah menjadi susunan bentuk-bentuk geometris. Dikatakan portrait karena WPAP yang dibuat selalu dalam posisi vertikal. Adapun pengertian portrait adalah sebuah bentuk atau ukuran yang memanjang secara vertikal, yang biasanya digunakan pada teknik fotografi untuk menangkap objek manusia (Rasyid, 2011: 23).

Di era modern saat ini WPAP mengalami perkembangan yang pesat. Rasa penasaran masyarakat terhadap WPAP semakin tumbuh dan makin banyak pelukis Indonesia yang menggunakan gaya pop art sebagai acuannya. Dan yang perlu diketahui juga bahwasanya WPAP tidak hanya dijadikan sebagai suatu karya yang mengekspresikan jiwa seni saja tetapi juga memiliki nilai jual atau nilai ekonomis dan sekaligus termasuk cara berekspresi dalam seni yang mana untuk memvisualisasikan objek manusia atau tokoh. Seperti apa yang di jelaskan oleh R. S. Stites, sebuah karya seni memiliki 3 nilai yaitu nilai kisah, nilai formal, dan nilai pakai. Nilai pakai sendiri bisa artikan nilai yang bersifat ekonomi yang berkaitan dengan uang.

Dalam analisis ini, kami membahas manfaat dari WPAP melalui media poster. Poster menurut Kustandi dan Sutjipto (2011:50) yaitu merupakan media komunikasi yang efektif untuk menyampaikan pesan singkat, padat, dan impresif, karena ukurannya yang relatif besar. Diungkapkan. Diungkapkan juga oleh Hasnun (2006:253) bahwa poster gambar atau tulisan di atas kertas atau kain yang dipasang di tempat umum berisi pemberitahuan. Juga Hasnun menambahkan isi tujuan dari poster sendiri berbeda-beda mulai dari imbauan, larangan, dan juga untuk ajakan untuk membeli produk atau untuk menghadiri acara. Maka dari itu dibuatnya poster ini guna untuk mengenalkan bahwa sebuah genre seni memiliki manfaat-manfaat yang belum tentu diketahui oleh masyarakat secara tidak sadar. Dan karena itu pula WPAP memiliki beberapa manfaat sebenarnya tidak hanya punya daya tarik dari segi penampilannya saja sebagai suatu karya visual, tetapi juga punya daya jual atau bisa dikatakan karya WPAP memiliki nilai ekonomis. Selain itu WPAP merupakan salah satu cara mengekspresikan jiwa seni untuk 
memvisualisasikan atau menggambarkan sosok seorang tokoh (objek manusia). Selain itu WPAP juga memiliki beberapa manfaat lainnya yang akan diurai dalam hasil dan pembahasan.

Melihat bagaimana poster memiliki peran penting dalam menyebarkan suatu informasi atau pengetahuan dengan menjadi media penyampaian, oleh karena itu, kami melakukan penelitian dengan melihat dan menganalisis penelitian orang lain. Kami melakukan analisa tentang fungsi/manfaat poster sebagai media penyampian informasi pengetahuan dengan melihat hasil penelitan yang telah dilakukan orang lain sebelumnya, dan juga melihat seberapa efektifnya penggunaan poster sebagai media penyampaian. Kami menganalisa hasil penelitian dari sebuah artikel publikasi karya Cindy Larasati yang berjudul "Pengembangan Media Pembelajaran Poster Untuk Meningkatkan Pengetahuan Siswa Terhadap Bencana Gempa Bumi di SMP Negeri 3 Gantiwarno". Adapun hasil analisanya serta poin yang dapat kami ambil untuk dipelajari yang berhubungan dengan artikel kami yaitu bahwa media poster dapat meningkatkan pengetahuan siswa terhadap gempa bumi, dengan beliau melakukan wawancara langsung yang merupakan uji kebutuhan kepada siswa dan guru untuk mendapat analisa kebutuhan, lalu beliau mulai merancang poster yang kriterianya sesuai dengan hasil wawancara tersebut. Adapun kesimpulan dari analisa serta perancangannya yaitu produk pengembangan media pembelajaran dengan menggunakan softwere Photoshop menghasilkan sebuah poster tentang materi gempa bumi. Poster dibuat sesuai dengan keinginan siswa dan guru melalui jawaban dari angket kebutuhan. Poster dibuat sesuai dengan kebutuhan siswa dan guru yaitu dengan menggunakan gambar yang berwana, poster dengan warna yang colorfull, poster dengan banyak gambar, dan materi yang singkat dan jelas.

Untuk tampilan poster, kami menganalisa contoh poster dari BNPB yang masih samasama poster yang berisikan informasi dengan tujuan mengedukasi. Poster tentang bencana gempa bumi yang berjudul "Jagalah Keselamatan Anda Semasa Gempa Bumi". Poster tersebut memiliki elemen visual yang terdiri dari gambar (ilustrasi), tipografi, warna, bidang, dan logo. Gambar yang digunakan dalam poster ini adalah gambar ilustrasi yang berbentuk animasi. Untuk tipografi, poster ini menggunakan jenis huruf san serif (tanpa kait) yang mungkin tujuannya untuk memudahkan audiens melihat meski dari jarak yang tidak dekat. Mengenai warna, poster ini terbilang colorfull, menggunakan banyak warna. Untuk bidang, terdapat 2 bidang 2 dimensi yang berbentuk lingkaran yang berada di pojok kiri atas. Sedangkan untuk logo, poster ini mencantumkan logo BNPB (Badan Nasional Penanggulangan Bencana) sebagai bentuk identitas organisasi yang menciptakan poster tersebut.

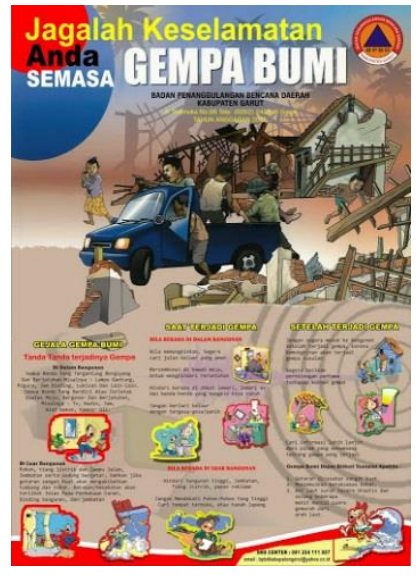

Gambar 1. Poster Mengenai Bencana Gempa Bumi yang dikeluarkan BNPB Sumber: DisasterChannel.co

\section{METODE PENELITIAN}

Pada penelitian ini, kami menggunakan pendekatan kualitatif. Menurut Sugiyono (2010: 1) penelitian kualitatif merupakan penelitian yang digunakan untuk meneliti kondisi subjek yang alamiah, dimana peneliti adalah sebagai instrumen kunci. 
Pendekatan kualitatif kami yaitu melakukan tinjauan pustaka dengan cara mengumpulkan bahan-bahan materi yang bersumber dari buku, artikel dan beberapa jurnal online. Jenis data yang digunakan yaitu data kualitatif (berbentuk kata-kata/kalimat). Dari metode ini, diperoleh data berupa data sekunder.

Data sekunder ialah "sumber data yang tidak langsung memberikan data kepada pengumpul data" (Sugiyono, 2008: 402). Misalnya seperti dari orang lain atau dokumendokumen. Data sekunder bersifat data yang mendukung keperluan data primer. Data sekunder yang kami gunakan dalam penelitian ini adalah artikel, jurnal dan buku online.

\section{HASIL DAN PEMBAHASAN}

\section{Pemahaman Tentang WPAP}

Lukisan pop art cenderung sangat cerah warna, biasanya merah, kuning, dan biru. Gambar dalam seni pop datar seperti yang ada di buku komik. Beberapa seniman juga menggunakan titik Ben-Day, sebuah metode yang dipinjam dari pencetakan buku komik (Sipperley, 2013: 12). Menurut Osterwold (2003: 44) pop art memberikan transparansi kontradiksi antara produk dan kenyataan. pop art memengaruhi periklanan, desain, dan industri kecil dan karenanya dikembalikan ke dunia sehari-hari dalam bentuk sampah, sampah bekas yang diproduksi oleh industri komunikasi massa parasite. WPAP (Wedha's Pop Art Potrait) merupakan gaya melukis pop art yang diciptakan oleh bapak Wedha pada era 1990-1991. Pada tahun tersebut bapak Wedha beranggapan menurunnya fungsi mata mengakibatkan kesulitan di dalam menyelesaikan karya-karya lukisan realisnya. Oleh karena itu bapak Wedha berfikir dan menemukan solusi untuk mengatasi masalah tersebut dan menciptakan gaya pop art yang diberi nama WPAP (Wedha's Pop Art Potrait) (Pramono, 2013: 24).

Wedha Abdul Rasyid adalah pelopor dari Wedha's Pop Art Potrait, dan karena itu beliau dikenal dan sering disebut sebagai bapak WPAP. Dalam pembuatannya, WPAP terdiri dari bidang geometris dan tidak diperbolehkan adanya kurva atau garis lengkung. Dalam karya WPAP sendiri, identik dengan penggunaan objeknya selalu wajah dengan posisi portrait. Namun dalam beberapa hal, WPAP sendiri jika diaplikasikan kedalam objek selain wajah, itu akan sedikit menghilangkan sebuah ke ciri khas dari aliran karya ini. Dalam karya WPAP tersebut bidang geometris dibentuk menyerupai wajah dan lalu diberikan warna-warna pop art. Dalam pewarnaannya pun terlihat juga pemberian warna gelap terang yang sesuai sehingga terlihat lebih spesifik dan mendetail. Hal ini diciptakan bapak Wedha dikarenakan faktor terbesarnya adalah daya penglihatan bapak Wedha yang mengalami penurunan karena usia lanjut.

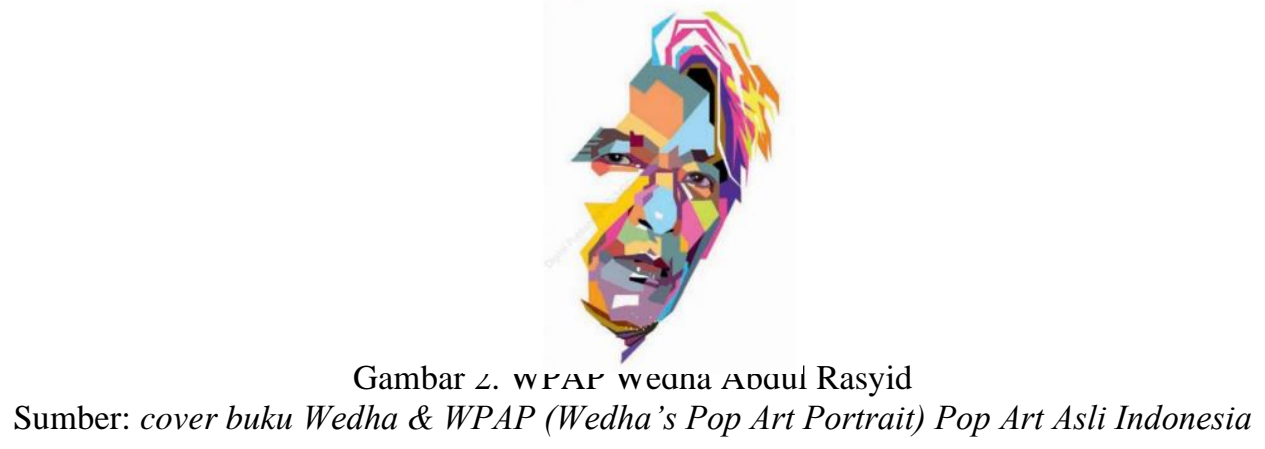

\section{Manfaat WPAP}

\section{Sebagai Media Mengekspresikan Seni}

Kita sudah sering mendengar kata seni pastinya dalam kehidupan sehari-hari. Namun apakah itu seni. Menurut Kamus Besar Bahasa Indonesia, kata seni memiliki beberapa arti. Arti tersebut adalah, pertama, keahlian membuat karya yang bermutu (dilihat dari segi kehalusannya, 
keindahannya, dsb). Kedua, karya yang dibuat dengan keahlian yang luar biasa, seperti tari, lukisan, ukiran. Ketiga, kesanggupan akal untuk menciptakan sesuatu yang bernilai tinggi (luar biasa). Seni menurut para ahli seperti Plato dan Rousseau adalah hasil peniruan alam dengan segala seginya. Dan juga Aristoteles mengungkapkan bahwa seni adalah harus dinilai sebagai suatu tiruan, yakni tiruan dunia alamiah dan dunia manusia.

Seni rupa menjadi salah satu media dalam mengekspresikan diri melalui gambar dan lukisan. Begitupun dengan WPAP yang merupakan salah satu dari karya seni rupa yang mana merupakan hasil dari mengekspresikan jiwa seni yang dimiliki oleh orang yang memang memiliki jiwa seni karena mencintai seni.

Membuat karya WPAP bisa dikatakan sebagai wadah atau media mengekspresikan jiwa seni dengan membuat lukisan gambar tiruan wajah manusia atau wajah tokoh sebagai objek utamanya yang terbentuk dari susunan bentuk domnasi geometris dengan posisi portrait dan warnanya terdiri dari warna-warna cerah.

Wedha Pop Art Portrait sebagai sebuah gerakan baru seni rupa kontemporer dengan banyak pengikut membawa angin segar bagi perkembangan seni rupa di Nusantara.

\section{Memiliki Nilai Ekonomis}

Seni sepenuhnya untuk sebuah dilihat keindahannya saja, melainkan seni bisa memiliki nilai ekonomi seperti hal yang dikemukakan oleh R. S. Stites. Bisa didapatkan bahwa WPAP pun bisa menjadi suatu karya seni yang bernilai ekonomis. Dalam penelitian yang di lakukan oleh Dawami (2016) yang berjudul "Eksistensi, Karya, dan Pemikiran Wedha Abdul Rasyid" disana di jelaskan bahwa WPAP bisa bernilai ekonomis diantaranya dengan beberapa momentum seperti adanya pengaruh dari budaya populer, industri kreatif, media sosial, isu nasionalisme yang di tuangkan dengan genre seni WPAP. WPAP mempunyai kekuatan dalam nilai ekonomi, dalam genre WPAP pun mendukung hal tersebut. Di zaman yang serba digital ini WPAP bisa banyak di gemari karena warna Pop Art nya dan bentuk geometris ciri khasnya yang menjadi alasan kenapa ini bisa menjadi suatu daya tarik. Masyarakat saat ini banyak yang menyukai suatu seni digital yang berwarna-warna terang seperti WPAP. WPAP juga tidak hanya di genre yang hanya di aplikasikan kedalam media kanvas saja, sekarang WPAP menjadi suatu genre yang bisa masuk ke dalam ranah digital bahkan hingga sempat menjadi populer pada masanya hingga dunia mengenal akan genre ini. Penggunaan dari genre WPAP ini dalam kegiatan ekonomi pun bisa seperti dari penjualan jasa pembuatan WPAP, poster, brosur, dan mechandise. Dari situlah WPAP menjadi suatu genre yang bisa bermanfaat dari sisi ekonomi. Selain menghasilkan juga ini dikerjakan dengan hobi dari si pembuat akan hal seni terutama seni genre WPAP yang diciptakan oleh Wedha Abdul Rashid.

\section{Media Memorial dan Apresiasi}

WPAP bisa dijadikan sebagai media memorial untuk tokoh atau orang yang telah tiada dikarenakan objek dari WPAP sendiri merupakan wajah manusia, sehingga tanpa disadari ini menjadi salah satu manfaat dari WPAP untuk menjadi media kenang-kenangan atau bahkan juga bisa jadi suatu penghargaan atau apresiasi atas jasa/kineja seseorang baik yang telah tiada maupun yang masih hidup.

\section{Media Pembelajaran}

Pop Art ciptaan bapak Wedha ini memang memiliki keunikan tersendiri disbanding karya lukis wajah pada umumnya. Hal ini karena WPAP adalah pop art yang dibuat tidak dalam prinsip realisme lagi, melainkan lukisan objek wajah manusia yang terbentuk dari berbagai bentuk geometris yang memiliki warna-warna berbeda yang mana gelap terangnya mengikuti bentuk lekukan wajah.

Proses pembuatan WPAP ini bisa menjadi media pembelajaran dalam bidang seni maupun desain secara digital, dimulai dari analisa bentuk wajahnya, sketsa wajah dengan menyusun bidang geometrisnya hingga proses pemberian warna pada setiap bidang geometrisnya. Karena membuat WPAP ternyata tidaklah mudah, tidak hanya asal membentuk bidang-bidang 
geometrisnya saja dan tidak asal dalam melakukan pewarnaan karena nanti hasilnya bisa tidak sesuai atau tidak mirip dengan wajah tokoh yang digambarkan.

\section{Media Promosi}

Trend design di Indonesia yang saya maksud di sini adalah kecenderungan orang-orang untuk mengikuti style yang sedang populer. Salah satu syarat untuk suatu desain agar menjadi trend adalah memiliki ciri khas yang sangat, sangat mencolok dibandingkan dengan desain lainnya. Yang kedua, desain tersebut harus cukup tersebar luas sehingga menarik perhatian masyarakat. Trend design di Indonesia terbesar adalah tipografi, vector portrait, low poly, flat design, dan WPAP.

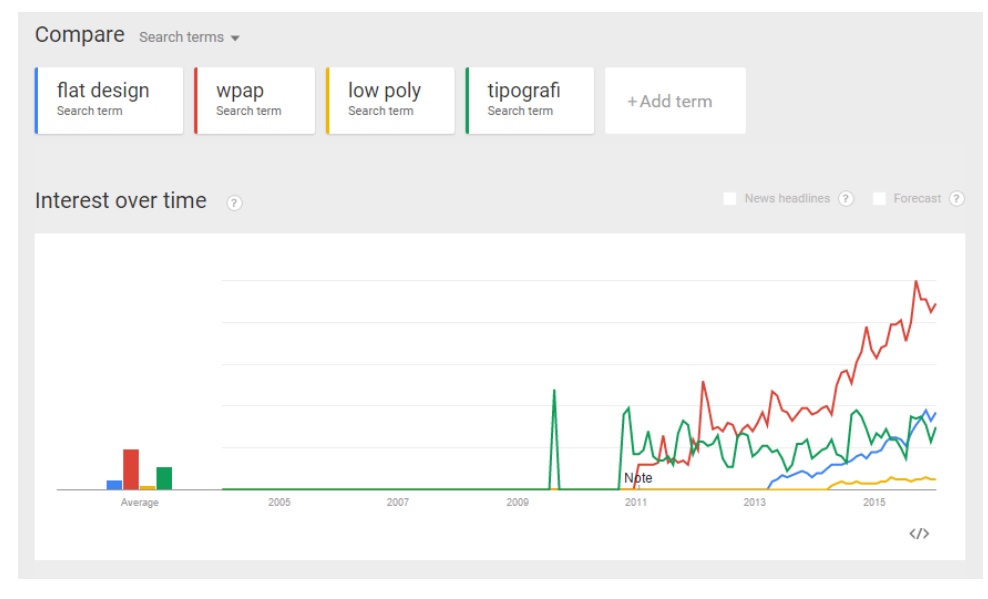

Gambar 3. Grafik Trend Desain

Sumber : https://infodigimarket.com/manfaat-trend-design-di-indonesia-untuk-media-promo/

Dari grafik tersebut bisa kita simpulkan bahwa desain yang paling popular di Indonesia saat ini adalah WPAP. WPAP atau Wedha's Pop Art Portrait sendiri merupakan seni potret wajah yang diciptakan oleh seniman grafis asal Pekalongan, Jawa Tengah, pada tahun 1990. Walaupun WPAP sudah ada sejak lama, namun popularitasnya mulai meningkat di awal tahun 2011, seperti yang terlihat pada grafik. Sejak tahun 2015 kemarin, kita mulai melihat desain bergaya WPAP diterapkan di mana-mana. Tetap saja, jika gaya ini kita terapkan secara berlebihan, hasilnya pun tidak enak dipandang. Hal ini juga berlaku untuk desain-desain lainnya. Jadi, bisa dikatakan bahwa WPAP merupakan karya seni yang dapat dijadikan sebagai salah satu media promosi dari sekian banyak media promosi lainnya.

\section{Media Penyampaian (Poster)}

Media yang kami gunakan untuk menyampaikan informasi mengenai manfaat-manfaat umum dari WPAP (Wedha's Pop Art Potrait) yaitu poster. Poster memiliki kekuatan untuk dicerna oleh orang yang melihat karenaposter lebih menonjolkan kekuatan pesan, visual dan warna. Hal tersebut sesuai dengan pandangan Nana Sudjana (2005: 51) bahwa poster adalah media yang kuat warna, pesan, dan maksud untuk menangkap perhatian orang yang lewat, tetapi cukup lama menanamkan gagasan yang berarti dalam ingatannya. Tujuan poster menangkap perhatian orang dengan menanamkan suatu makna tertentu yang ingin disampaikan pembuat poster.

Dalam poster ini, kami akan menyebutkan secara ringkas apa saja manfaat dari WPAP serta menampilkan salah satu contoh WPAP nya. Tujuan kami dalam pembuatan poster ini yaitu untuk memberikan pemahaman serta informasi berupa pengetahuan tentang manfaat WPAP yang mungkin tidak semua orang ketahui.

\section{Proses Pembuatan Poster}




\section{Tahapan Mencari Ide atau Konsep}

Sebelum ke tahap sketsa dan pembuatan secara digital, pencarian dan penentuan ide atau konsep menjadi bagian paling awal. Pencarian ide ini dengan research dengan tema yang sesuai dengan pembahasan manfaat WPAP.

1. Konsep Perancangan

Dalam ini Potrait wajah Wedha dalam illustrasi WPAP tersebut terlihat Discord.

Discord sendiri ialah ekstrim kontras terdiri dari berbagai unsur, kontras warna, shape, ukuran, dan arah (Arsad Arfial, 1984). Ditambahkan beberapa ornament pendukung visual sekaligus pengisi ruang agar tampak tidak terlalu kosong. Dalam hal ini menjadi sebuah kesatuan atau unity, keselurahan elemen yang ada pada poster ini menjadi satu kesatuan. Menurut Hakim (1984:37-119) menjabarkan bahwa dalam mendesain ada proses dimana unsur-unsur yang mendukung desain tersebut mengalami penyatuan secara utuh dalam suatu media, yang akhirnya menjadi hubungan individu terhadap objek-objek visual.

2. Layout

Dengan memperhatikan dan mempertimbangkan segala yang telah di sketsa, poster dibuat dengan menggunakan elemen seperti gambar, typografi, warna, garis, dan bidang. Pada layout yang digunakan yaitu pembagian menjadi dua space, yang pertama untuk menaruh WPAP wajah Wedha untuk menekankan illustrasi WPAP nya dan dibagian kedua yang berwarna kuning langsat untuk diberikan informasi akan WPAP dan manfaat-manfaatnya. Dan dalam poster ini diinput gambar WPAP berwajah Wedha sebagai penegas informasi.

3. Warna

Menurut Putri (2012) yang mengutip dari Russel dan Verill dalam bukunya Otto Klepprers's Advertising Procedure $(1986,416)$ warna dapat digunakan untuk, menarik perhatian, menjadi penekanan pada elemen tertentu dalam desain, dan warna dapat menunjukan mood tertentu dalam kesan psikologis. Untuk warna, pada poster ini digunakan 2 warna sebagai background yaitu warna kuning langsat (bawah) dan abu-abu muda (atas) dan untuk warna typografinya yaitu biru dongker agar menimbulkan kekontrasan dengan background.

\section{Tipografi}

Untuk tipografi menggunakan jenis huruf san serif (tanpa kait) sehingga lebih mudah dibaca dan terlihat lebih jelas meskipun memiliki jangkauan jarak. Dan tulisannya pun berisikan kalimat-kalimat yang menjelaskan manfaat dari WPAP.

\section{Tahapan Perancangan Sketsa Kasar}

Awal dalam pembuatan poster ini, yaitu kami membuat dan merancang sketsa kasar dengan menggunakan pensil. Sketsa kasar ini diperuntukan sebagai landasan awal sebelum masuk ke proses pengaplikasian digital. Perancangan dibuat dengan mempertimbangkan posisi bentuk poster yaitu portrait, dan memperkirakan posisi serta letak-letak elemen posternya seperti yang tampak pada gambar 2. 


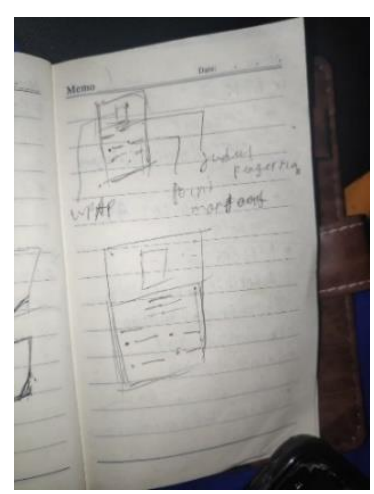

Gambar 4. Sketsa Kasar Poster Manfaat WPAP

\section{Pengaplikasian ke Media Digital atau Visual Digital}

Setelah dari proses perancangan sketsa kasar, selanjutnya masuk ke proses pengaplikasian digital. Di proses ini, hasil dari sketsa kasar dibuat ke media digital dengan menggunakan perangkat software di laptop yaitu Adobe Illustartor CC.

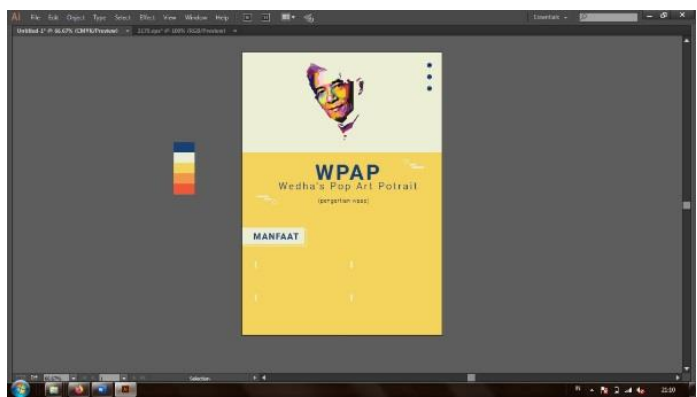

Gambar 5. Pengaplikasian sketsa kasar WPAP ke media digital

\section{Finishing}

Finishing merupakan proses akhir sekaligus penyelesaian dari seluruh proses. Pada proses ini, sketsa poster yang telah diaplikasikan ke media digital melalui software Adobe Illustrator CC kemudian di save dalam bentuk JPEG dengan ukuran A4 dan resolusi 300 dpi. Poster ini dapat ditampilkan untuk keperluan digital (postingan di media sosial) maupun diprint (cetak).

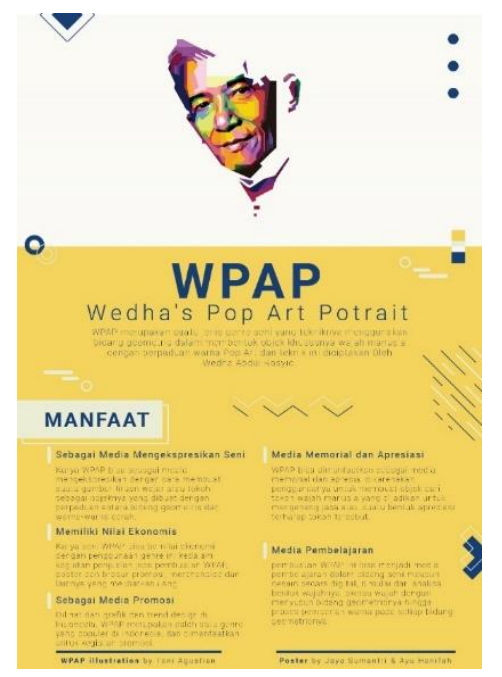

Gambar 6. Tampilan Poster "Manfaat WPAP" 


\section{SIMPULAN}

Pop Art yang diciptakan oleh Wedha Abdul Rasyid atau yang kita kenal dengan WPAP (Wedha's Pop Art Potrait) merupakan karya lukis digital berbentuk portrait dengan objek wajah tokoh yang memiliki beberapa manfaat umum. Adapun manfaat-manfaat yaitu sebagai media mengekspresikan seni, karya yang memiliki nilai ekonomis, media memorial dan apresiasi, dan media pembelajaran. Untuk dapat menyampaikan informasi sekaligus pengetahuan mengenai manfaat WPAP ini, dibutuhkan media penyampaian informasinya. Melalui sebuah poster, kami menyampaikan informasi sekaligus pengetahuan singkat tersebut. Proses pembuatannya pun melalui 3 tahap yaitu perancangan sketsa kasar (manual), pengaplikasian ke media digital dan terakhir finishing. Poster ini terdiri dari elemen-elemen seperti gambar, typografi, warna, garis, dan bidang. Adapaun tujuan kami dari perancangan media ini pun sebagai media penyampaian secara visual 2D manfaat WPAP.

\section{DAFTAR PUSTAKA}

Hakim, A. A. (1984). Nirmana dwimatra (Desain dasar dwimatra). Yogyakarta: Penerbit Andi.

Averinfo. (2016). Manfaat trend design di Indonesia untuk media promo.

Dani. (2019). Konsep seni: Pengertian dari berbagai aspek. Dikases dari https://bocahkampus.com/cara-menulis-daftar-pustaka.

Dawami, A. K. (2016). Wedha's pop art potrait (Wpap): Eksistensi, karya, dan pemikiran Wedha Abdul Rasyid (Doctoral dissertation, INSTITUT SENI INDONESIA SURAKARTA).

Felix, J. (2012). Pengertian seni sebagai pengantar kuliah Sejarah Seni Rupa. Humaniora, 3(2), 614-621.

Hasnun, A. (2006). Pedoman menulis untuk siswa SMP dan SMA. Yogyakarta: Andi.

Kustandi, C., \& Sutjipto, B. (2011). Media pembelajaran manual dan digital. Bogor: Ghalia Indonesia.

Larasati, C. (2017). Pengembangan media pembelajaran poster untuk meningkatkan pengetahuan siswa terhadap bencana gempa bumi di SMP Negeri 3 Gantiwarno. Skripsi. Surakarta: Pendidikan Geografi, Fakultas Keguruan dan Ilmu Pendidikan, Universitas Muhammadiyah Surakarta.

Maarif, Y. S. (2017). Kreativitas wedha's pop art portrait. Pantun Jurnal Ilmiah Seni Budaya, $1(2), 68-77$

Megawati, M. (2017). Pengaruh media poster terhadap hasil belajar kosakata bahasa Inggris (Eksperimen di Sdit Amal Mulia Tapos Kota Depok). Getsempena English Education Journal, 4(2), 217637.

Munandar, U. (2004). Pengembangan emosi dan kreativitas. Jakarta: Rineka Cipta.

Osterwold, T. (2003). Pop art. Italy: Taschen.

Pramono, Y. L. (2013). Kajian tentang karya WPAP (Wedha's Pop Art Portrait). Surakarta: Universitas Sebelas Maret. 
Putri, S. F. C. (2012). LKP: Desain layout pada surat kabar Radar Surabaya sebagai upaya menarik minat pembaca (Doctoral dissertation, STIKOM Surabaya).

Rasyid, W. A. (2013). Wedha \& WPAP (Wedhas Pop Art Portrait). Jakarta: Elex Media Komputindo.

Sipperley, K. (2013). A look at pop art. Florida: Rourke Educational Media. 